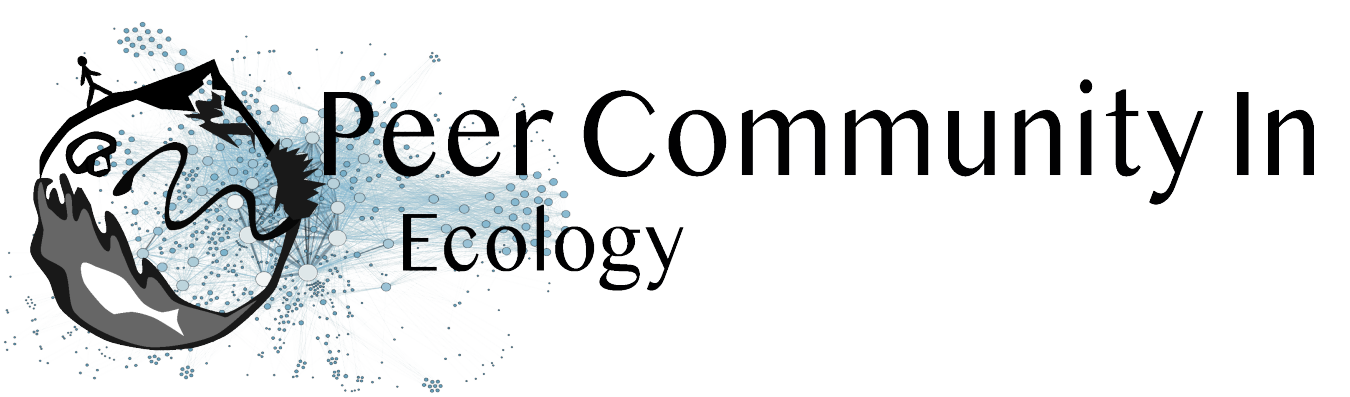

Open Access

RECOMMENDATION

\title{
Does elevated parasite richness in the environment affect daily path length of animals or is it the converse? An answer bringing some new elements of discussion.
}

Cite as: Sueur C. Does elevated parasite richness in the environment affect daily path length of animals or is it the converse? An answer bringing some new elements of discussion. Peer Community In Ecology, 100001 (2018). DOI:

10.24072/pci.ecology.100001

Published: 10th June 2018

Based on reviews by:

anonymous

anonymous

Correspondence:

cedric.sueur@iphc.cnrs.fr

\section{(c) 9 CC-BY-ND 4.0}

This work is licensed under the Creative Commons

Attribution-NoDerivatives 4.0 International License.

\section{Cédric Sueur}

Institut Pluridisciplinaire Hubert Curien, Université de Strasbourg - Strasbourg, France

\section{A recommendation of \\ Charpentier MJ and Kappeler PM. A reply to 'Ranging Behavior Drives Parasite Richness: A More Parsimonious Hypothesis'. arXiv:1805.08151 ver 2 peer-reviewed and recommended by PCI Ecology (2018). http://arxiv.org/abs/1805.08151}

In 2015, Brockmeyer et al. [2] suggested that mandrills (Mandrillus sphinx) may accept additional ranging costs to avoid heavily parasitized areas. Following this paper, Bicca-Marques and Calegaro-Marques [1] questioned this interpretation and presented other hypotheses. To summarize, whilst Brockmeyer et al. [2] proposed that elevated daily path length may be a consequence of elevated parasite richness, Bicca-Marques and Calegaro-Marques [1] viewed it as a cause. In this current paper, Charpentier and Kappeler [3] respond to some of the criticisms by Bicca-Marques and Calegaro-Marques and discuss the putative parsimony of the two competing scenarios. The manuscript is interesting and focuses on an important question concerning the discussion about the social organization and home range use in wild mandrills. This answer helps to move this debate forward and should stimulate more empirical studies of the role of environmentally-transmitted parasites in shaping ranging and movement patterns of wild vertebrates. Given the elements this paper brings to the topics, it should have been published in American Journal of Primatology, the journal that published the two previous articles. 


\section{References}

[1] Bicca-Marques JC and Calegaro-Marques C. Ranging behavior drives parasite richness: A more parsimonious hypothesis. American Journal of Primatology 78 (2016), 923-927. DOI: 10.1002/ajp.22561.

[2] Brockmeyer T, Kappeler PM, Willaume E, Benoit L, Mboumba S, and Charpentier MJE. Social organization and space use of a wild mandrill (Mandrillus sphinx) group. American Journal of Primatology 77 (2015), 1036-1048. Dol: 10.1002/ajp.22439.

[3] Charpentier MJ and Kappeler PM. A reply to 'Ranging Behavior Drives Parasite Richness: A More Parsimonious Hypothesis'. arXiv:1805.08151 ver 2 peer-reviewed and recommended by PCI Ecology (2018). http://arxiv.org/abs/1805.08151.

\section{Appendix}

Reviews by anonymous and anonymous, DOI: 10.24072/pci.ecology.100001 